\title{
LA SIERRA MILITARIZADA: IMAGINARIO GEOGRÁFICO DEL GENOCIDIO EN LA NARRATIVA PERUANA CONTEMPORÁNEA
}

The militarized Andes: geographic imaginary of genocide in contemporary peruvian narrative

\section{RESUMEN}

Este artículo problematiza el imaginario geográfico de la sierra en las novelas peruanas que ficcionalizan el tiempo presente y posterior al conflicto armado entre Sendero Luminoso y el Estado Peruano. Las novelas Un lugar llamado oreja de perro (2008) de Iván Thays y Sangre de la aurora (2013) de Claudia Salazar elaboran el imaginario de la sierra como un territorio de postguerra que responde a paradigmas biopolíticos y geomilitares contemporáneos de extrema violencia (Mbembe). Estas narrativas se entroncan con una vasta tendencia de la literatura peruana que ha ficcionalizado la sierra andina como elemento constitutivo del imaginario nacional pero trasmuta el imaginario de locus amoenus en un locus horridus. En las novelas analizadas, la geografía de la sierra se transforma en un espacio de exterminio de las comunidades indígenas y en un territorio militarizado que ejerce violencia sobre la memoria del genocidio; por tanto, la experiencia del espacio se vuelve repulsiva.

Palabras claves: Thays, Salazar, imaginario espacial, locus horridus, territorio.

\section{UNIVERSUM \\ MARÍA TERESA \\ JOHANSSON}

Universidad Alberto Hurtado, Chile.

Correo electrónico:

mtjohans@uahurtado.cl

ORCID: 0000-0003-3488-2032

ResearchGate:

Scholar.google:

Academia.edu:

Este artículo forma parte del proyecto de investigación FONDECYT 1150904 "Post-narrativas de la violencia: representaciones y desplazamientos de la memoria y la ficción en la literatura peruana (2000-2015)" del cual la autora fue co-investigadora. La primera versión de este trabajo se presentó como ponencia en el Congreso de SOCHEL, Valparaíso, 2018.

Artículo recibido el 30 de noviembre, 2019. Aceptado el 7 de febrero, 2020.

Web: http://universum.utalca.cl | ISSN: 0716-498X - 0718-2376 


\begin{abstract}
The present article problematizes the geographical imaginary of the sierra in Peruvian novels that fictionalize the present and post-conflict period between Sendero Luminoso and the Peruvian state. The novels Un lugar llamado oreja de perro (2008) by Iván Thays and Sangre de la aurora (2013) by Claudia Salazar elaborate the imaginary of the sierra as a post-war territory that responds to contemporary biopolitical and geomilitary paradigms of extreme violence (Mbembe). These narratives are connected with a vast tendency of Peruvian literature that has fictionalized the Andean highlands as a constituent element of the national imaginary and transmutes an imaginary of locus amoenus into a locus horridus. In the novels analyzed, the geography of the sierra is transformed into a space for extermination of indigenous communities and a militarized territory that exerts violence on the memory of genocide; therefore, the experience of space becomes repulsive.
\end{abstract}

Keywords: Thays, Salazar, space imaginary, locus horridus, territory.

Durante los años del conflicto armado entre Sendero Luminoso y el Estado Peruano, el territorio andino se constituyó en un escenario de guerra multifocal. Este escenario se suscitó tras la emergencia de un movimiento revolucionario militarizado que ejerció acciones terroristas y la inmediata acción de despliegue de las fuerzas armadas que utilizaron una estrategia represiva antisubversiva de carácter genocida, la que además alentó la implicación de los comuneros indígenas en las acciones de autodefensa. Si bien el conflicto se extendió por todo el territorio nacional, fue la región de la sierra el principal escenario de muerte y la región de Ayacucho, la más devastada.

La representación literaria de esta violencia política, que dejó más de ochenta mil muertes, ha sido objeto de vastas investigaciones que complejizan la relación entre los procedimientos ficcionales y la cuestión del referente histórico, tensionan los paradigmas tradicionales de los géneros narrativos ante la representación de la experiencia límite y problematizan la dicotomía víctima-victimario al interior de un debate en torno a la noción de otredad que atiende al reconocimiento de problemáticas de raza e ideología implicadas en los procesos de memoria. ${ }^{1}$ En estas direcciones, una vasta producción de la

1 El proyecto "Post-narrativas de la violencia: representaciones y desplazamientos de la memoria 
crítica literaria peruana y latinoamericana (Vich, Vivanco, Franco, Moraña, entre otros), se ha dedicado durante las últimas décadas a interpretar la complejidad de la representación de la violencia en la producción literaria y cultural.

Con este campo problemático como trasfondo, este trabajo se orienta a interrogar la categoría de imaginario espacial y geográfico al interior de una narrativa que ha configurado la sierra andina como espacio de violencia extrema. Específicamente, se trata de interpretar el modo en que las nuevas generaciones de autores complejizan la dimensión del espacio geográfico, vinculándose y distanciándose de un imaginario nacional de larga data que ha construido el territorio de la sierra con distintas valoraciones, sentidos e imágenes.

Este artículo plantea que en las novelas Un lugar llamado oreja de perro de Iván Thays y Sangre de la aurora de Claudia Salazar, se produce una nueva y extrema configuración del territorio de la sierra peruana, modelada por paradigmas biopolíticos y geomilitares contemporáneos. En estas narrativas, el emplazamiento de la violencia extrema en los poblados de la sierra andina provoca una transformación en el imaginario nacional que históricamente configuró este territorio con una fuerte carga simbólica e identitaria. En este sentido, una aproximación geopolítica y geocrítica a las novelas de Thays y Salazar permite dar cuenta del ensamble entre los imaginarios geográficos nacionales y una nueva configuración del espacio de la sierra, en términos de espacio social, paisaje natural y ambiente local, que es afectado por los estados jurídicos y militares impuestos sobre el territorio.

En la interpretación del imaginario espacial y geográfico de estas narrativas se articulan tres dimensiones que actualizan y vinculan aspectos geoculturales, literarios y sociopolíticos. Estas dimensiones problematizan la cuestión de la zonificación geográfica como matriz geocultural del imaginario

y la ficción en la literatura peruana (2000-2015)" ha tenido el objetivo de analizar las operaciones de transformación de las disputas ideológicas, de los imaginarios narrativos y de los procedimientos ficcionales en una nueva generación de la narrativa peruana mediante un foco de atención puesto en las formas discursivas, los géneros ficcionales y testimoniales, las retóricas y los tropos específicos utilizados para elaborar los procesos de memoria social 
nacional peruano; el espacio literario de la sierra andina signado por una heterogeneidad cultural constitutiva $\mathrm{y}$, finalmente, el carácter de zona bajo estado de sitio o emergencia y de zona militarizada impuesto por el Estado Peruano sobre el territorio de la sierra en el desarrollo y fin del conflicto armado. Por su parte, una aproximación geocrítica permite ensamblar los imaginarios geográficos nacionales con la narrativa que elabora una experiencia actualizada del espacio en los niveles de la percepción de un ambiente, del paisaje y de los estados de excepción del orden jurídico sobre el territorio. Respecto de este último punto, es interesante recordar el foco propuesto por Achille Mbembe (2011), en relación con los territorios militarizados del mundo colonizado. Las consideraciones planteadas por Mbemebe giran en torno a las relaciones entre lo político y la muerte en los sistemas coloniales contemporáneos que funcionan bajo estados de emergencia, en los que la soberanía se identifica con un biopoder que establece un control sobre las poblaciones y una práctica de segregación racial: “En estas situaciones, el poder (que no es necesariamente un poder estatal) hace referencia continua e invoca la excepción, la urgencia y una noción "ficcionalizada" del enemigo"(21). Mbembe ahonda en la relación entre la soberanía sobre poblaciones y territorios y el derecho de matar, y con este fin propone una integración entre las nociones de biopolítica y los conceptos de estados de excepción y de sitio. Si bien se trata de una conjunción teórica ya elaborada por Agamben a partir de la integración de los postulados de Arendt y Foucault, Mbembe enfatiza consideraciones coloniales y postcoloniales en su análisis de las trayectorias mediante las cuales el estado de excepción y la relación de enemistad conforman la base normativa para que opere el derecho de matar. En el escenario del conflicto armado interno, la guerra y el genocidio acaecidos en el Perú, operó justamante un indiscriminado derecho a matar a amplias poblaciones segregadas en un territorio atravesado por las violencias postcoloniales. En este contexto, la sierra andina peruana vendría a integrarse a lo que Mbembe denomina "las topografías reprimidas de la crueldad" (75). 


\section{LA SIERRA EN EL IMAGINARIO GEOGRÁFICO CULTURAL Y LITERARIO DE LA NACIÓN PERUANA}

El imaginario geográfico nacional del Perú basa su representación territorial en tres zonas que lo constituyen, a saber: la costa, la sierra y la selva, siendo la costa el espacio urbano cosmopolita habitado por criollos y la sierra un espacio que históricamente ha resguardado la "identidad primigenia" de la nación. En contraposición a la costa y a la selva, la sierra ha sido comprendida tradicionalmente como el espacio para el emplazamiento de la etnia andina, lo que ha producido el imaginario de una geografía física y humana específica que Arguedas denominó la "nación cercada". Ya en 1928, en sus Siete ensayos de interpretación de la realidad peruana, Mariátegui había enfatizado una perspectiva espacial para analizar las desigualdades políticas y económicas de la nación al identificar las diferencias sociales entre la sierra y la costa y exponer tempranamente la consideración de que el ambiente, la naturaleza y la geografía no constituyen una externalidad respecto de los procesos socioeconómicos, sino que los condicionan. Tal como sostiene Quiroz Rojas (2017) desde una perspectiva geográfica, Mariátegui ensambla la lectura de la colonialidad crítica, de matriz histórica, con la geografía física y humana "al momento de sumergirse en su crítica capitalista del Perú” (205). Efectivamente, Cornejo Polar señala que, a partir de los años veinte, Mariátegui reitera el esquema de las tres regiones internas, pero insiste sobre todo en que "la costa y la sierra son dos regiones en que se distingue y separa, como el territorio, la población generando con esto la dualidad de la historia y del alma peruanas" (204-205). Por tanto, las profundas diferencias sociales, culturales y económicas entre los habitantes del Perú, así como su injusticia estructural, se disponen y determinan en y por los territorios geográficos. De hecho, la consideración de los habitantes de la sierra como campesinos e indígenas se gestó en los albores de la república cuando, "en el curso de la segunda mitad del XIX, el término indio pasó a estar intrínsecamente asociado con la sierra, y la palabra serrano 
adquirió una marcada connotación despectiva" (Méndez, 2011).

Bajo la perspectiva de los estudios culturales contemporáneos, el crítico literario Víctor Vich (2010) interpreta los distintos imaginarios culturales de la sierra y sostiene que, en primer lugar, esta ha sido inventada por la modernidad peruana como "un lugar estático, resistente a la noción de cambio" (158) en el que impera "un orden temporal diferente" (158) y donde sobresalen los signos de la precariedad y estancamiento. Según el autor, el criollo peruano habría sostenido sobre este espacio una mirada orientalista ante una otredad que era necesario documentar y fotografiar. Desde otro ángulo, solidario con el anterior, "el segundo imaginario sostiene que la modernidad peruana inventó a la sierra como una realidad degradada y abyecta" (159). Esta degradación implica, evidentemente, la exclusión de lo político, de lo tecnológico y de las formas productivas modernas.

Por otra parte, sin necesariamente contradecir lo propuesto por Vich, es posible afirmar que una orientación de esta modernidad periférica también levantó tempranamente una imagen de la sierra como un locus amoenus al crear un imaginario identitario utópico, donde la posibilidad de emergencia de una comunidad de iguales en un territorio generoso, abundante y de tintes paradisíacos, se hacía posible. Así lo confirma la emergencia de la revista mensual La Sierra en el año 1927, que convocó a destacados escritores y artistas y fue un órgano de la denominada Juventud Renovadora Andina, que tuvo entre sus colaboradores a Manuel González Prada y J. Guillermo Guevara. En su proclama vanguardista, y siguiendo las ideas de Luis Emilio Valcárcel compiladas en su libro Tempestad en los Andes, la revista consagró el andinismo como una suerte de ethos cultural y geográfico caracterizado por un modo de vida comunitario y en sintonía con la naturaleza. En palabras de Cornejo Polar, el proyecto de Valcárcel, que esplendoriza el pasado para encontrar el futuro, sería "una utopía inversa, regresiva, que se lanza a la reconquista del paraíso perdido" (154). Cabría agregar que ese paraíso perdido tiene una forma terrenal transmutada: las figuras edénicas de la montaña y del valle fértil. 
Estas rupturas excepcionales con los estereotipos del retraso, mayormente arraigados en el imaginario social, originaron una alianza de la modernidad vanguardista con el indigenismo, generando una temprana literatura de crítica social que puede leerse también en la obra de César Vallejo. Sin duda, el heredero de esta tendencia y el más importante impulsor de la sierra como un escenario en que convive la máxima injusticia social con una forma de vida comunitaria basada en valores humanos primigenios fue, en las décadas posteriores, José María Arguedas, quien se resistió a exotizar el territorio y optó por una comprensión de las complejidades de la identidad cultural peruana en términos de heterogeneidad. De manera sincrónica a la producción literaria de Arguedas, los conflictos políticos iniciados a fines de los sesenta reinscribieron las imágenes de extrema pobreza y de sublevación social del campesinado organizado, las que más tarde dieron una explicación al surgimiento del movimiento de guerrilla en la década de los sesenta y luego, fueron usadas para interpretar sus inéditas y extremas reemergencias a inicios de los ochenta, con los movimientos de Sendero Luminoso y el MRTA.

\section{EL IMAGINARIO GEOGRÁFICO DE LA SIERRA Y LAS NARRATIVAS DEL CONFLICTO ARMADO}

Tal como se planteó al comienzo del artículo, históricamente no cabe duda de que si bien el conflicto armado se extendió hacia la costa y la selva, fue la sierra el principal escenario de la devastación y la provincia de Ayacucho, la más agraviada. Según Víctor Vich, la exacerbación del imaginario de la violencia y la barbarie sobre la sierra andina tuvo su punto más álgido en el conflicto armado entre el Estado y Sendero Luminoso: "la sierra se volvió entonces, un lugar atroz e imposible" (163). Siguiendo esta idea, es posible sostener que la noción de lugar atroz e imposible redunda en la representación literaria de un locus horridus, una forma extrema del espacio de violencia sobre poblaciones indígenas que se sitúa, por lo demás, en las antípodas del locus amoenus. Para generar esta representación literaria, varias narrativas han 
seguido una de las matrices narrativas nacionales más clásicas y han optado por relatar la trayectoria del sujeto urbano limeño que se desplaza hacia la sierra para conocer un espacio otro, que debe ser documentado por fotógrafos y periodistas.

Las novelas Un lugar llamado Oreja de Perro de Iván Thays y La sangre de la aurora de Claudia Salazar reiteran el motivo del viaje del sujeto urbano a la sierra. Mientras la primera novela tiene como protagonista a un periodista, la segunda presenta a una fotógrafa como uno de sus personajes principales. Estas narrativas refieren el lugar central que tuvo la actividad de los fotógrafos en la documentación del conflicto armado, cuando este era una externalidad absoluta e ignorada en la capital costera. ${ }^{2}$ Así, ambas novelas dialogan de manera crítica con el temprano texto de Vargas Llosa Historia de una matanza sobre los sucesos de Ucchurajay. En este, se relata el viaje de un grupo de periodistas y fotógrafos a la sierra ayacuchana, quienes serán asesinados por comuneros quechuahablantes tras ser confundidos con senderistas en Huanta. Recordemos que Vargas Llosa encabezó la comisión investigadora de estos asesinatos, a pedido del gobierno, porque inicialmente se creyó que había personal del ejército involucrado en la masacre. En Historia de una matanza, Vargas Llosa enfatiza que el espacio de la sierra es un territorio arcaico en el que aún convive el mundo colonial con la degradación indígena. Sin embargo, en su representación de las comunidades campesinas mantiene presente, al mismo tiempo, los resabios de una naturaleza romántica. ${ }^{3}$

2 Yuyanapag. Para recordar. Relato visual del conflicto armado interno en el Perú, 1980-2000, proyecto fotográfico comisionado por la propia Comisión de Verdad y Reconciliación, es justamente el epítome de esta cuestión.

3 Tal como explica Enrique Mayer, la redacción del Informe y los argumentos que ahí se esgrimen dieron paso a una amplia polémica y a serios cuestionamientos sobre la representación de los indígenas: "En la imagen nacional de algunos intelectuales, los comuneros no podían ser ni tan violentos, ni tan ignorantes, ni tan ingenuos como los pinta el informe. Muy emblemático de este debate fue la frase suelta del General Noel, que muy probablemente los comuneros de Uchuraccay habían confundido las cámaras fotográficas de los periodistas con armas de fuego. Esta declaración enfureció a los críticos y Vargas Llosa intentó responderla en su Informe. Se pregunta el autor: “¿Están en condiciones los comuneros de Uchuraccay de identificar una cámara fotográfica y saber para qué sirve? Algunos de ellos, por lo menos sin ninguna duda...No es éste el primer caso de una sociedad en la que el primitivismo y el arcaísmo culturales pueden coexistir con el uso de ciertos productos manufacturados modernos" (Vargas Llosa et al. 1983: 23)" (9). 
Décadas después, Thays y Salazar reactualizan críticamente la figura del periodista y fotógrafo en el viaje de la costa a la sierra. La novela de Thays configura la sierra desde la mirada cínica de un periodista que se adentra en una zona de postconflicto militarizada. El relato ficcionaliza un estado de emergencia que permite la presencia militar subordinada a la autoridad civil. ${ }^{4}$ Por su parte, La sangre de la aurora se adentra en la sierra siguiendo la figura moral testimoniante de una joven fotógrafa limeña que rompe con los cánones heteronormativos y viaja a la sierra en el momento más álgido del conflicto. El territorio se encuentra bajo un estado de sitio al mando de las disposiciones de la autoridad militar. Junto a esta figuras foráneas ambas novelas vuelven a indagar y explorar la posibilidad y la imposibilidad de representación de la subjetividad indígena mediante figuras de mujeres, ya sea mestiza, campesina, habitante rural o migrante de distintos pueblos y pequeñas ciudades en la región de Ayacucho.

\section{POSTCONFLICTO Y MILITARIZACIÓN DEL TERRITORIO. UN LUGAR LLAMADO OREJA DE PERRO}

La novela se sitúa en la localidad de Oreja de Perro, nombre referido a una comunidad campesina ubicada en el distrito de Chunqui que fue visitada por la Comisión de Verdad y Reconciliación en el año 2002. Si bien el título refiere a una locación geográfica particular e insinúa un ensamble entre espacio ficcional y referencial, la primera página del libro explicita la preeminencia del primero sobre el segundo: "Oreja de Perro es el nombre con que se conoce a una zona ubicada en La Mar (Ayacucho) que incluye varios caseríos, algunos de ellos de muy difícil acceso. Aunque, lamentablemente, el lugar fue en efecto muy golpeado por el terrorismo en la década de los años ochenta, todos los datos sobre la zona, los lugares mencionados y los personajes que aparecen en esta novela son ficticios" (s/p). De esta manera,

4 Es necesario anotar que, en el año 2003, el presidente Toledo declaró estado de sitio por huelgas durante dos meses. 
el texto hace explícito que el autor ingresará a un espacio literario, en el que reelaborará los resabios del imaginario nacional sobre la sierra ensamblados esta vez con un contexto histórico y espacial referencial localizable.

Thays sitúa la narración en los tiempos posteriores al conflicto armado, al término del ejercicio de la Comisión de Verdad y Reparación, y plantea una posición crítica respecto de los usos políticos de las mínimas reparaciones estatales. La labor de reparación apoyada por quienes realizan la labor de la comisión es fuertemente enjuiciada e ironizada en el relato bajo la figura de los jóvenes estudiantes de antropología que prestan asistencia. Estos limeños foráneos, de cuyo grupo el mismo narrador forma parte, llegan a la sierra como extranjeros para documentar, registrar y presenciar el evento presidencial mientras pasan el tiempo en encuentros juveniles de carácter festivo. En este sentido, se vuelve a citar el imaginario de la sierra, propuesto por Vich como aquel espacio documentado y registrado por una mirada foránea. Así, la novela produce un imaginario del territorio determinado por el contexto político nacional. Esto hace posible reunir en el pueblo de la serranía a los agentes estatales, gobierno, militares, periodistas y ayudantes de la Comisión de la verdad y reconciliación, junto a los campesinos, niños y otros habitantes del lugar.

Por otra parte, la novela vuelve preeminente un estado de duelo que es el tenor afectivo que acompaña los procesos posteriores a los contextos de extrema violencia. Tal como sostiene Mabel Moraña: "Es evidente que entre los dos términos de la ecuación oficialista definida durante el gobierno de Alejandro Toledo, entre Verdad y Reconciliación, se extiende, desafiante, el abismo oscuro del duelo y la necesidad inaplazable de justicia, el espacio no regulado del resentimiento y los biopoderes que han llegado a constituir el “orden" social de la modernidad" (187-188). En la lectura de esa temporalidad del "después", tanto Moraña al reflexionar sobre los memoriales, como una serie de críticos que ahondaron en la lectura del libro de Iván Thays, hacen referencia a la persistente modulación del duelo en términos personales y colectivos. En esta línea, la crítica literaria ha sostenido que la novela privatiza el duelo al poner en escena la experiencia personal de un escritor periodista 
que ha perdido a su hijo. Tal como sostiene de Vivanco (2013), "la dimensión problemática de la puesta en relato no recae en la instancia colectiva, sino en la privada. El periodista no asume ningún suceso que no haya vivido personalmente: es al lector a quien le corresponde transferir las huellas de la violencia, desde el individuo hacia el colectivo" (148).

Así, el narrador periodista en estado de duelo, junto a un sarcástico y grotesco fotógrafo de nombre Scamarone, se han desplazado desde la capital a la sierra para cubrir el evento de la llegada del presidente Toledo, quien entregará una reparación monetaria a los campesinos que fueron víctimas de la violencia. Las fotos de Scamarone, que ha recorrido las guerras del mundo, retratan a funcionarios públicos. La cámara no denuncia sino que está domesticada y al servicio de los intereses de una democracia tutelada por la frivolidad mediática.

La estadía del protagonista en el poblado de Oreja de Perro se extiende por apenas dos días durante los cuales se establecen nuevas relaciones afectivas, se retoma el tópico del exotismo en el encuentro entre el criollo y la serrana y se retrata, con distanciamiento, a diferentes sujetos sociales. Esto sucede al tiempo que el protagonista se mantiene sumido en su conflicto doloroso de la pérdida del hijo y de la separación de la pareja. Esta dinámica de relaciones subjetivas y sociales, marcadas por el vacío y la angustia, se vuelve solidaria con una experiencia del espacio que tiende a percibirse de manera subjetiva como degradado, estéril e incluso repulsivo. En este sentido, la narración configura desde el inicio un locus horridus en el cual se expone una degradación humana y económica extendida hacia la naturaleza, los animales y el mundo vegetal: "La zona más deprimida del país, sembrada de fosas comunes, de intrincado acceso [...] la más golpeada por el terrorismo, la más miserable, fría, yerta" (13). La imagen que propone la narración es extrema puesto que el paisaje de la tierra, antaño considerada como generosa pachamama, ha sido inoculado por los restos del genocidio, configurando así un paisaje de naturaleza asociado a la absoluta carencia de vida. Se trata de un espacio "imposible" para la vida social en el que la propia naturaleza está calcinada: "Mientras nos alejamos veo una columna de humo. En las montañas 
están quemando el follaje" (189).

No obstante lo anterior, el paisaje natural conserva algunos rasgos provenientes del imaginario nacional tradicional sobre la sierra en la figuración de las altas cumbres y el cielo abierto de las serranías, pero, en todos los casos, estos elementos aparecen despojados de cualquier tipo de adjetivación que los califique o los valore en términos positivos. Efectivamente, la mera insinuación de algún atributo es prontamente deconstruida por el narrador, el que redunda en la permanencia de las sensaciones desagradables que este paisaje le produce: "Los cerros tienen algo bello, algo intenso en sus lomos alzados, pero empiezan a causarme angustia" (130). O bien: "Huele a barro, un olor meditabundo. Huele a lluvia, esporas, telarañas, oscuridad" (22) Las condiciones geográficas de las serranías, asociadas a la altura y la consecuente oscilación térmica, afectan también, y sobremanera, a la corporalidad del narrador y producen un impacto negativo en la vitalidad del sujeto: "Empiezan los primeros síntomas del mal de altura. Dolor de cabeza, náuseas, agotamiento, ojos hinchados" (30). La sintomatología de un permanente malestar corporal que incluye náuseas, diarreas, cefaleas, es producida por el territorio geográfico que impacta directamente sobre la salud corporal provocando en el narrador una disminución de sus fuerzas vitales. Además, la falta de salubridad en el espacio, por la precarización y la pobreza de las viviendas, carga la experiencia de la espacialidad con una particular amenaza de enfermedades contagiosas: "El cuarto empieza a oler a diarrea. El baño se ha desbordado. El olor a difteria, a enfermedad" (124). En este sentido, los espacios interiores y exteriores se vuelven espejos de una redundante sensación que oscila entre la repulsión en el espacio interior y el más tenue desagrado en el exterior, donde el espacio social se percibe reprimido y amenazado por la violencia de las fuerzas armadas. En la novela, la violencia de la ocupación territorial es retratada en una espeluznante escena en la que un militar golpea a un perro en la plaza pública ante la mirada de los campesinos, quienes no se pronuncian ante la afrenta. A la vista de las mujeres quechuahablantes, la escena de la violencia extrema sobre el animal se torna en un teatro amenazador que recuerda la fuerte desmesura represiva que se ejerció sobre la población indígena durante 
el conflicto y que pervive como una latencia que puede volver a emerger.

Dadas todas las dimensiones que se integran en este imaginario espacial, es posible sostener que Oreja de Perro no es solo una localidad referencial configurada como un pueblo andino, ni tampoco es únicamente una entidad geográfica que se expresa mediante una representación paisajística de la naturaleza y de la tierra degradada, sino que además es un espacio de negación de lo político que se acerca a la noción que Mbembe utiliza al hablar de un tipo de territorio colonial ocupado en el que la soberanía se define como el derecho a dar muerte a los pueblos, es decir, un espacio de carácter necropolítico. En este sentido, cabe recordar el planteamiento de Mbembe, quien sostiene que: "Vivir bajo la ocupación contemporánea es experimentar de forma permanente la "vida en el dolor": estructuras fortificadas, puestos militares, barreras incesantes, interrogatorios, palizas, toques de queda ..." (72-73).

En este territorio militarizado, devastado, estéril, que provoca rechazo y malestar, no se expone ningún rastro de lo que fuera el sujeto colectivo indígena en un estado de conciencia social, organización o rebelión ante el exceso de poder. En principio se trata de una representación muy disminuida de la agencia política: "Con tantos militares y policías, los huraños campesinos prefieren estar en su casa a estas horas" (130). La escena emblemática de la revuelta, presente en varias narrativas peruanas de la sierra, es absolutamente omitida. Por el contrario, en esta configuración del espacio de la sierra y del pueblo, se instala un sujeto campesino pasivo y degradado. Los campesinos, sin nombre, aparecen en la novela fusionados en parte con el paisaje. A excepción de Jazmín, joven que habita la localidad, "una chola", quien fuera víctima de la violencia estatal y militar contra su madre y en el presente está embarazada de un militar luego de una probable violación. En cierto sentido, el narrador se vuelve solidario con el autoritarismo que rige el espacio social, pues al representar el pueblo indígena replica la política estatal nacional limeña de desprecio en la mirada hacia la otredad además de repetir la conservadora metáfora de romance entre la serrana chola y el periodista limeño. 
Es importante señalar que no hay en la textualidad ningún rastro del universo quechuahablante, ni de romanticismo utópico, ni de discursos indigenistas reivindicatorios. En la representación de los habitantes de la localidad aparece el discurso de la degradación y la vejez, y los campesinos se vuelven solidarios con el espacio de la ciudad, carente y despojado. Las descripciones son elocuentes: "Algunos campesinos se unen en círculos, vestidos con pantalones remangados y chompas viejas, incluso poncho" (180). La cualidad de lo inerte se impone también sobre los habitantes: "La ciudad es de piedra, las personas parecen de piedra" (189).

Estas imágenes del espacio y sus habitantes se tornan legibles para pensar una política de la muerte, en el tiempo presente, que se concibe en términos de violencia militar. En las palabras de Mbembe, hay una estrecha conexión entre la política de la muerte, las armas y la creación de mundos de muerte en los que "numerosas poblaciones se ven sometidas a condiciones de existencia que les confieren estatus de muertos-viventes" (75). En la novela Un lugar llamado Oreja de Perro todo el territorio y el espacio social del pueblo andino se vuelve una zona militar. La última imagen de la muerte es el cadáver de un militar apedreado ante el cual el narrador se pregunta: “¿Cómo se mata a un militar en un pueblo enano con docenas de militares? También hay más militares. Y perros" (188). Así, los militares se vuelven también objeto representacional de la muerte, es decir han copado íntegramente el espacio ficcional de Oreja Perro y el imaginario de la sierra andina se identifica como el de la sierra militarizada.

\section{LA SIERRA COMO ESPACIO DE EXTERMINIO Y RESISTENCIA DE LAS COMUNIDADES INDÍGENAS}

A diferencia de la novela de Thays, La sangre de la aurora de Claudia Salazar se sitúa en la temporalidad en que el conflicto armado está sucediendo. Si bien se trata de un referente histórico ya abordado por otras narrativas, Salazar opta por incorporar una nueva perspectiva de género que inscribe distintas figuras femeninas en su calidad de agentes y no únicamente de 
víctimas del conflicto. En razón de lo anterior, la novela se divide en tres relatos que se fragmentan y superponen para construir al personaje de la senderista, la campesina quechuahablante y la fotógrafa limeña. Sin duda, la perspectiva feminista de esta narración es una de sus mayores contribuciones a la hora de hacer justicia a la representación de las mujeres en las narrativas de la memoria del conflicto.

Los relatos de las mujeres se construyen tres visiones diferenciadas de la sierra andina, la que, si bien se configura como un espacio de guerra extremo en el que la violencia interviene y actúa sobre las imágenes de la naturaleza y de los pueblos andinos, despliega distintas modulaciones. La representación del territorio lo expone arreciado por la violencia que proviene de todos los frentes: senderistas, militares, sinchis, comuneros participan en una serie de acciones crueles, inclementes y criminales en secuencias narrativas que llevan al límite la posibilidad misma de la representación. A partir de lo anterior, esta novela construye la sierra como un espacio de exterminio, sin límites jurídicos, que ampara las prácticas genocidas en una articulación sin precedentes entre tecnologías militares y violencias primitivas, las que exponen una convivencia de machetes, piedras, explosivos, fusiles y ráfagas de metralletas. La sierra en tanto zona en estado de sitio se confirma como un espacio de exterminio y expone una "topografía de la crueldad" extrema.

Esta exacerbación hiperbólica de la violencia se instala en distintas espacialidades como caseríos, campos abiertos y también recintos carcelarios, escenarios en los que se despliegan las formas tecnológicas militares junto a otras más rudimentarias y primitivas para torturar el cuerpo de la mujer indígena y cometer asesinatos selectivos y masivos.

Las imágenes expresan el fin radical del espacio social, político y vital de los pueblos de la sierra. En estos ya no hay posibilidad de vida social, porque se han convertido en pueblos fantasmas, marcados por el abandono: "un pueblo que parece casi desierto. Cada vez hay menos comuneros en los pueblos por los desplazamientos forzados o voluntarios" (58). La carencia y la escasez son extensivas a todo el orden animal y vegetal: "un par de gallinas picotean mecánicamente el esqueleto de un choclo" (53). Asimismo, 
la narración radicaliza la imagen de la incineración en la versión extrema de la quema de cadáveres: "Estamos a pocos metros de la plaza y hay varios puntos donde se detectan hogueras humeantes. El olor comienza a ser insoportable. Algo chamuscado o podrido. Náuseas. El pueblo es una humareda" (65). En una clara referencia a las narrativas de Auschwitz (Levi, Semprún, entre otros), el relato remite a la percepción olfativa asociada a la imagen de horror. En este sentido, la fotógrafa que narra este apartado está corporalmente afectada por la percepción de esta experiencia límite de estar dentro de un locus horridus. El paisaje de la sierra ha sido devastado; las imágenes de las fotografías tomadas por la joven limeña y reveladas a su regreso a Lima son elocuentes al respecto. Cortadas, desenfocadas, solo hacen visible la imagen de la catástrofe en los cuerpos que yacen fuera de foco y la imposibilidad de visualizar al pueblo: "Ahí está el pueblo envuelto en la humareda. Ese olor que jamás me soltará" (78). Nuevamente la experiencia sensorial y olfativa aparece como un indicador del espacio que se hace cuerpo y memoria del conflicto.

Tal como sucedía en la novela de Thays, junto a la desaparición de los pueblos, ha desaparecido también la posibilidad de inscribir una representación del paisaje de naturaleza romántica o de valores positivos asociados a la sierra. La referencia a la naturaleza de la sierra solo opera en términos metafóricos como símil del cuerpo femenino de la mujer indígena, una imagen embestida por la violencia del ejército: "partimos la montaña, quebramos la aurora, penetramos la tierra" (73). No obstante lo anterior, en el relato de Jacinta, la mujer indígena, la configuración de la sierra tiene una modulación distinta ya que el territorio conserva un principio vital que metaforiza la propia existencia de la indígena serrana. Si bien la imagen de la naturaleza está degradada y disminuida, se conserva la posibilidad de equiparar la subjetividad femenina con atributos de la naturaleza provenientes de la pachamama: "A nadie le iba a contar yo que un día me fui a dejarla a mi bebita por el río. ... ¿Qué sería de su vida sin mí?, acaso una pampa sin animales, un río triste, un cerro pelado" (81). En esta novela se intenta restituir la representación del sujeto indígena mediante la integración de tradiciones indigenistas y propiamente indígenas. La autora actualiza una sintaxis con un rastro de bilingüismo junto a la inscripción 
somera del universo quechuahablante en distintos apartados: "Pachacuti entre los edificios, pachacuti en la capital, bomba" (89), actualizando una tradición de escritura que ampara un sujeto social activo.

Tanto en La sangre de la aurora como en Un lugar llamado Oreja de Perro, el territorio en que habita la comunidad ha sido degradado en sus niveles: naturales, sociales y políticos. De esta manera, y teniendo en cuenta la importancia de la zonificación geográfica y la particular configuración de la sierra andina en el imaginario nacional y literario peruano, estas novelas sobre el conflicto armado han configurado el espacio geográfico de la sierra como un espacio distópico, que no solo expone la transformación de la representación tradicional del imaginario geográfico nacional, sino que también elabora el espacio de la sierra como un complejo mecanismo discursivo generado en el ensamble entre indicios referenciales de locación espacial y temporal (que pueden leerse tanto en los nombre de los pueblos o ciudades como en las referencias a los sucesos históricos en ellos acontecidos); en la reinscripción de los distintos imaginarios nacionales de larga data (en los que sobresalen las citas a las representaciones del indigenismo, la crítica a los rasgos del romanticismo de naturaleza y los residuos del andinismo); y finalmente, la configuración de un espacio biopolítico en el que el escenario de la sierra se configura como espacio concentracionario, de genocidio y de memoria del trauma. Por tanto, en estas novelas, la sierra andina se representa como un imaginario espacial y geográfico que es justamente el escenario del genocidio pero también un espacio de violencia y devastación que se proyecta más allá del término del conflicto armado bajo los órdenes de la militarización. En este sentido, la configuración espacial y geográfica de la sierra que ambas novelas elaboran, expresa filiaciones y rupturas con una larga tradición del imaginario nacional que les antecede. 


\section{REFERENCIAS}

Cornejo Polar, Antonio (2011). Escribir en el aire: Ensayos sobre la heterogeneidad socio-cultural en las literaturas andinas. Centro de estudios literarios Cornejo Polar: Lima.

De Vivanco, Lucero (2013). "Postapocalipsis en los Andes. Violencia política y representación en la literatura peruana reciente". Taller de letras N. ${ }^{\circ}$ 52: 135-151.

Mayer, E. "Uchuraccay y el Perú profundo de Mario Vargas Llosa". https:// www.verdadyreconciliacionperu.com/admin/files/articulos/1927 digitalizacion.pdf (consultado el 8 de Octubre de 2019).

Mbembe, A. (2011). Necropolítica. España: Melusina.

Méndez Gastelumendi, Cecilia (2001). "De indio a serrano: nociones de raza y geografía en el Perú (siglos XVIII-XXI)” Histórica. Vol.35 Núm. 1.

Moraña, Mabel (2012). "El ojo que llora: biopolítica, nudos de la memoria y arte público en el Perú de hoy" en Latinoamérica. Revista de Estudios Latinoamericanos (México 2012/1): http://www.redalyc.org/pdf

Quiroz Rojas, Rodolfo (2017). "El imaginario geográfico de José Carlos Mariátegui: de las diferencias de ambiente a la coexistencia política revolucionaria", Izquierdas, 34, julio 2017: 203-230

Salazar, Claudia (2013). La sangre de la aurora. Animal de invierno: Lima. Thays, Iván (2008. Un lugar llamado Oreja de Perro. Anagrama: Barcelona. Vich, Victor (2010). "El discurso sobre la sierra del Perú: la fantasía del atraso". C y E. Año II n³ Primer semestre, 157-168. 